\title{
Demographic, clinical, laboratory, and genetic risk factors associated with COVID-19 severity in adults: A narrative review
}

\author{
Helena Martynowicz ${ }^{1, A-D, F}$, Anna Jodkowska ${ }^{1, B-E}$, Rafał Poręba $a^{1, C, E, F}$, Grzegorz Mazur ${ }^{1, C, E, F}$, Mieszko Więckiewicz 2,A,E,F \\ ${ }^{1}$ Department and Clinic of Internal and Occupational Diseases, Hypertension and Clinical Oncology, Wroclaw Medical University, Poland \\ ${ }^{2}$ Department and Division of Experimental Dentistry, Wroclaw Medical University, Poland \\ A - research concept and design; $\mathrm{B}$ - collection and/or assembly of data; $\mathrm{C}$ - data analysis and interpretation; \\ $D$ - writing the article; $E$ - critical revision of the article; $F$ - final approval of the article
}

Address for correspondence

Anna Jodkowska

E-mail:anna.jodkowska@umed.wroc.pl

Funding sources

None declared

Conflict of interest

None declared

Received on November 23, 2020

Reviewed on December 3, 2020

Accepted on December 18, 2020

Published online on February 24, 202

Cite as

Martynowicz H, Jodkowska A, Poręba R, Mazur G, Więckiewicz M. Demographic, clinical, laboratory, and genetic risk factors associated with COVID-19 severity in adults: A narrative review. Dent Med Probl. 2021;58(1):115-121. doi:10.17219/dmp/131795

DOI

$10.17219 / \mathrm{dmp} / 131795$

Copyright

○) 2021 by Wroclaw Medical University

This is an article distributed under the terms of the

Creative Commons Attribution 3.0 Unported License (CC BY 3.0)

(https://creativecommons.org/licenses/by/3.0/).

\begin{abstract}
Since the first report on it in December 2019 in Wuhan, China, the novel coronavirus disease 2019 (COVID-19) has rapidly spread throughout the world. Due to the lack of effective therapy available for COVID-19 patients, the identification of risk factors for the severe course of the disease is a matter of urgency. Therefore, the aim of this review was to report on evidence-based risk factors affecting the severity and prognosis of COVID-19. We searched the PubMed database for current literature to identify relevant publications concerning risk factors for COVID-19 severity. Demographic and social factors (age, gender, race, in-center communities/nursing homes), clinical factors (smoking, hypertension, obesity, diabetes, chronic lung diseases, cardiovascular diseases - CVD, chronic kidney disease - CKD, malignancies, dementia, cardiomyopathies, immunocompromised state), laboratory markers (C-reactive protein - CRP, leukocytosis, ferritin, interleukin (LL)-6, D-dimer, lactate dehydrogenase - LDH, aspartate aminotransferase - AST, procalcitonin, creatinine, Iymphopenia, IL-2, IL-7, IL-10, granulocyte colony-stimulating factor - G-CSF, also known as colony-stimulating factor 3 - CSF 3, interferon gamma-inducible protein-10 - IP-10, monocyte chemoattractant protein-1 - MCP-1, macrophage inflammatory protein-1alpha - MIP1A, tumor necrosis factor alpha - TNF-a), and genetic factors related to both the virus and the host were discussed. The identification of the potential risk factors affecting the severity and prognosis of COVID-19 may provide a chance for earlier and more effective management of COVID-19.
\end{abstract}

Key words: risk factors, severity, demographics, COVID-19, SARS-CoV-2 


\section{Introduction}

Coronavirus disease 2019 (COVID-19) is a viral disease caused by severe acute respiratory syndrome coronavirus-2 (SARS-CoV-2). Currently, the outbreak of the COVID-19 pandemic has become a major clinical threat all over the world. The World Health Organization (WHO) declared the outbreak of COVID-19 as a worldwide pandemic in March 2020. Globally, as of November 19, 2020, there have been 55,928,327 confirmed cases of COVID-19, including 1,344,003 deaths, reported to WHO. ${ }^{1}$ Based on genomic and phylogenetic studies, SARS-CoV-2 might originate from bat coronaviruses, although its exact origin remains unknown. ${ }^{2-4}$

The novel coronavirus is believed to be contagious during its incubation period, commonly observed as 3-7 days and being reported as up to 14 days. ${ }^{5}$ The transmission of SARS-CoV-2 from patients who have not yet developed symptoms has been reported in numerous studies. ${ }^{6-8}$ Coronavirus disease 2019 presents a wide variety of clinical manifestations. The most common symptoms of the disease which have been reported repeatedly include fever, cough, fatigue, muscle pain, headache, and dyspnea. Some other symptoms, such as diarrhea, expectoration, loss of taste and/or smell, hemoptysis, nasal obstruction, or runny nose, have been reported less frequently. ${ }^{9,10} \mathrm{Re}$ cently, the immune system has been recognized to play a critical role in providing preexisting immunity to SARSCoV-2. ${ }^{11-13}$ Lymphopenia has been commonly observed in COVID-19, with levels more profound in more severe cases, ${ }^{14,15}$ while peripheral bilateral ground-glass opacity or consolidation in chest computed tomography (CT) scans have been reported as the most common radiological finding. ${ }^{16}$

The spectrum of COVID-19 symptoms ranges from asymptomatic and mild symptomatic cases to a severe hyperinflammatory state, followed by acute respiratory distress syndrome (ARDS) and death. ${ }^{14,17}$ The severity of the disease has been categorized as a mild, moderate, severe, and critical condition. ${ }^{18,19}$ Fortunately, up to $40 \%$ of SARS-CoV-2 infections may be asymptomatic, suggesting that some people could be protected from the disease. ${ }^{20}$ More than $80 \%$ of the infected patients present no more than mild symptoms, resembling a common cold with a dry cough, fatigue and fever. ${ }^{10,21}$ In mild cases, dyspnea, the clinical evidence of pneumonia and respiratory insufficiency have not been observed, while resting blood oxygen saturation $\left(\mathrm{SpO}_{2}\right)$ remained usually above $93 \%{ }^{22,23}$ Patients with moderate disease suffer from fever, respiratory symptoms or pneumonia. In severe disease, dyspnea and hypoxemia occur, with the respiratory rate reaching 30 breaths/min or more and $\mathrm{SpO}_{2} \leq 93 \%$ under resting conditions. ${ }^{24}$ In the most severe COVID-19 cases, ARDS, multiple organ dysfunction syndrome (MODS), shock, and coagulation abnormalities have been observed. ${ }^{25-27}$ Severe cases of COVID-19 presenting with respiratory failure require early and prolonged support with mechanical ventilation. ${ }^{28}$

Risk factors for COVID-19 severity are complex and comprise demographic, clinical, laboratory, and genetic factors, concerning both the host and the virus variability. Until now, apart from symptomatic treatment, there is no evidence known for the effective causative therapy of COVID-19. ${ }^{29,30}$ Therefore, identifying the main risk factors affecting the severity and prognosis of COVID-19 seems to be of particular importance. Hence, the aim of this narrative review was to report on evidencebased risk factors affecting the severity and prognosis of COVID-19.

\section{Methods}

The authors searched the PubMed database to identify relevant publications published between January 2020 and November 2020, and presenting demographic, clinical, laboratory, and genetic COVID-19 risk factors. The following inclusion criteria were used: original and review articles that discussed risk factors for the severity and outcome of COVID-19; the availability of the full text of the article; and papers published in the English language.

\section{Demographic, social and clinical factors}

Numerous studies have demonstrated that elderly patients are more likely to experience severe COVID-19 manifestation than their younger counterparts. ${ }^{31}$ Older age ( $>65$ years), male gender and obesity have been stated as the most common risk factors, ${ }^{32,33}$ with age reported so far as the strongest determinant of the severity of the disease. ${ }^{9,34,35}$ Also, social risk factors, typically inconducive to social distancing, have been reported to be of great importance. Thus, the COVID-19 pandemic has affected a large proportion of nursing home residents, with higher prevalence in the in-center dialysis community. ${ }^{35,36}$ The Epidemiology Working Group for NCIP Epidemic Response has demonstrated comorbidities to be an important risk factor as well. ${ }^{34}$ Cardiovascular diseases (CVD), arterial hypertension (HTA), diabetes, ${ }^{37-39}$ chronic lung diseases, ${ }^{40-42}$ severe asthma, ${ }^{43}$ neoplasms, ${ }^{44,45}$ and chronic kidney disease (CKD), especially under dialysis treatment, have been reported to increase the risk of COVID-19 severity and morbidity. ${ }^{32,35,46-48}$ It has been recently reported that even a younger age of $\geq 60$ years is associated with a major risk. ${ }^{31,49}$ It has been calculated that the risk of COVID-19 unsuccessful outcome in people aged $>80$ years is increased more than twentyfold when compared to 50-59-year-old individuals. ${ }^{43}$ Presumably, the age-related diminishing of the physiological activity of both respiratory and cardiovascular systems 
provides a good explanation for the impaired clearance of pathogens. ${ }^{50,51}$ Taking into account the dysfunction of arterial endothelium, nitric oxide (NO) availability - the main intracellular antiviral defense - decreases significantly in the elderly. ${ }^{52}$ Zhou et al. showed that older age, the initial Sequential Organ Failure Assessment (SOFA) score $>2$, D-dimer $>1 \mu \mathrm{g} / 1 \mathrm{~mL}$, and the respiratory rate $>24$ breaths $/ \mathrm{min}$ were independent risk factors for COVID-19 mortality in the Chinese population. ${ }^{53}$ Also dementia was described as associated with a higher mortality rate in a study of 16,749 patients hospitalized for COVID-19. ${ }^{54}$ Among symptoms, dyspnea has been recognized as an independent risk factor for the severity of the disease. Furthermore, a significant association between COVID-19 severity and the smoking status has been demonstated. ${ }^{48,55}$

Another significant risk factor for COVID-19 severity which has been noted is race. Black, South Asian and minority ethnic groups have been reported to be at higher risk of the poor outcome of COVID-19 as compared to Caucasians, even after the adjustment for other factors. ${ }^{43,56,57}$

In an observation of 1,289 oncological patients with solid tumors, age and the use of corticosteroids before COVID-19 diagnosis, together with thoracic primary tumor site, were independently associated with COVID-19 severity. ${ }^{58}$ Except cytotoxic chemotherapy, associated with a slight increase in the risk of death, none of the anticancer drug protocols administered during the 3 months preceding COVID-19 had a significant effect on its mortality or severity. It is worth emphasizing that $39 \%$ of patients had their systemic anticancer treatment interrupted or stopped following COVID-19 diagnosis. ${ }^{58}$

According to the Center for Disease Control and Prevention (CDC), the most important risk factors for COVID-19 severity are cancer, CKD, chronic obstructive pulmonary disease (COPD), heart failure, coronary artery disease, cardiomyopathies, immunocompromised state from solid-organ transplant, obesity, Down syndrome, pregnancy, sickle-cell disease, smoking, and type 2 diabetes. ${ }^{59}$ Regarding the pathophysiological importance of endocrine-immune-vascular interactions for the clinical course of COVID-19, metabolic syndrome has also been suspected to increase the risk of the severe course of COVID-19. ${ }^{60}$ However, some data is inconsistent, which might be caused by the limited samples size or the presence of multiple confounding factors. ${ }^{61-63}$ In the Chinese population, hypertension, diabetes and CVD were independently associated with COVID-19 severity, which was confirmed in a recent meta-analysis. ${ }^{64}$ Despite initial controversies at the early stage of the pandemic, the use of angiotensin-converting enzyme inhibitors (ACEIs) and angiotensin II type 1 receptor blockers (ARBs) could contribute to the improvement of COVID-19 outcome in hypertensive patients. ${ }^{65}$ Recently, a prospective observational cohort study based on the data collected in the Risk stratification in COVID-19 patients in the ICU (RISC19-ICU) registry showed that the main mortality predictors in critically ill COVID-19 patients were oxygenation deficit, and renal and microvascular dysfunction, together with coagulatory activation. ${ }^{66}$

The severity of COVID-19 might also be related to the amount of viral load, which has been observed to be higher in patients with severe COVID-19 than those with mild COVID-19. ${ }^{67}$

\section{Laboratory risk factors}

The monitoring of laboratory markers serves as a sensitive indicator of the severity of the disease, important for clinicians. Elevated levels of C-reactive protein (CRP), ferritin, interleukin (IL)-6, and plasma D-dimer are usually observed during infection. Hypercoagulability marked as elevated D-dimer concentration has been described to be indicative of poor COVID-19 prognosis. ${ }^{68,69}$ Recently, IL- 6 has been identified as the key predictor of mortality in COVID-19. ${ }^{53}$ As SARS-CoV-2 originates from China, most of former studies regarding COVID-19 severity refer to the Chinese population. Huang et al. showed higher plasma levels of IL-2, IL-7, IL-10, granulocyte colonystimulating factor (G-CSF), interferon gamma-inducible protein-10 (IP-10), monocyte chemoattractant protein-1 (MCP-1), macrophage inflammatory protein-1alpha (MIP1A), and tumor necrosis factor alpha (TNF- $\alpha$ ) in COVID-19 intensive care units (ICU) patients. ${ }^{10}$ It has also been demonstrated that leukocytosis, high scores on the modified quick SOFA, an elevated serum level of aspartate aminotransferase (AST) (more than 3 times), and a serum level of creatinine of $2 \mathrm{mg} / \mathrm{dL}$ or more are markers of a significantly higher risk of ICU admission and mortality in COVID-19 patients. ${ }^{70}$ The neutrophilto-lymphocyte ratio has also been reported to be one of the major predictors of COVID-19 severity. ${ }^{71}$

A recent meta-analysis confirmed that reduced levels of lymphocytes and hemoglobin, elevated leukocytosis, AST, alanine aminotransferase (ALT), blood creatinine, blood urea nitrogen, high-sensitivity troponin, creatine kinase, high-sensitivity CRP, IL-6, D-dimer, ferritin, lactate dehydrogenase (LDH), and procalcitonin, and a high erythrocyte sedimentation rate were risk factors for severe COVID-19. ${ }^{72}$ In the Chinese population, total protein and albumin concentrations have also been identified as independent risk factors for severe disease. ${ }^{48}$ Lactate dehydrogenase and prealbumin have been demonstrated to be associated with the severity of the disease. The mortality risk is associated with age, LDH, CRP, D-dimer, and lymphopenia in patients with comorbidities. ${ }^{73,74}$ An independent association between glycated hemoglobin $\left(\mathrm{HbA}_{1 \mathrm{c}}\right)$ and COVID-19 death rate has been also revealed..$^{75-77}$ Based on the secure health analytics platform which covers $40 \%$ of all patients in England (OpenSAFELY), 
it has been shown that a $\mathrm{HbA}_{1 \mathrm{c}}$ level of at least $58 \mathrm{mmol} / \mathrm{mol}$ is associated with a higher risk of COVID-19-related death. ${ }^{43}$ Recently, IP-10 and MCP-1 have been demonstrated to be novel biomarkers of COVID-19 severity, which may be related to the risk of patients' death from COVID-19. ${ }^{78}$

\section{Genetic factors}

\section{SARS-CoV-2 genetic diversity}

Coronaviruses are RNA viruses that belong to order Nidovirales, family Coronaviridae and subfamily Coronavirinae. ${ }^{79}$ The genome of one strain of SARS-CoV-2 is 29.9 kilo-bases $(\mathrm{kb})$ in size, with 29,891 nucleotides ${ }^{80}$ encoding 9,860 amino acids. ${ }^{81}$ There are 2 types of SARS-CoV-2 ( $\mathrm{L}$ and $\mathrm{S}$ ), which are defined by means of 2 different single nucleotide polymorphisms (SNPs). ${ }^{82}$ In a study comparing SARS-CoV-2 genetic diversity in mild and severe cases, it was demonstrated that the consensus sequences of all viruses were very similar, showing more than $99.8 \%$ sequence identity, regardless of the severity of the disease. ${ }^{83}$ However, patients with severe symptoms exhibited a significantly higher number of variants in coding and non-coding regions as compared to mild cases, and it was concluded that within-host diversity might play a role in the development of severe disease outcomes in COVID-19 patients, particularly among the older ones. ${ }^{83}$ Shikov et al. demonstrated that several rare ACE2 variants, including rs146598386, rs73195521, rs755766792, and others, were likely to affect the outcome of COVID-19. ${ }^{84}$ Among the accessory SARSCoV-2 proteins, ORF3a is the largest one, containing 274 amino acids. ${ }^{85}$ The potential role of ORF3a mutations in an elevated mortality rate for the SARS-CoV-2 infection through host immune evasion and immoderate cytokine storm has been recently shown. Majumdar and Niyogi revealed a decent association between SARS-CoV-2 ORF3a mutations and a higher mortality rate. ${ }^{86}$

\section{Human genetic diversity}

Recently, ABO blood groups have been implicated in susceptibility to the SARS-CoV-2 infection. Blood group A has been found to be associated with a minimally increased risk of acquiring COVID-19 in comparison with non-A groups; moreover, blood group $\mathrm{O}$ has been associated with a minimally decreased risk of acquiring COVID-19 in comparison with non-O groups. ${ }^{25,87,88}$ The $\mathrm{Rh}(\mathrm{D})$ positive blood type was associated with the SARS-CoV-2 infection and death. ${ }^{89}$

The renin-angiotensin-aldosterone system (RAAS) is of great importance in COVID-19,90 having considered the fact that angiotensin-converting enzyme 2 (ACE2) is the major receptor for SARS-CoV-2 on alveolar epithelial cells. ${ }^{91}$ Transmembrane protease serine 2 (TMPRSS2)
- a molecule that is necessary for spike protein (S protein) priming - and ACE2 are expressed, except alveoli, also in blood vessels, olfactory epithelium, the brain, the heart, the kidneys, the bladder, and the intestine, thus explaining the varied symptoms observed in COVID-19 patients. ${ }^{92,93}$ Together with ACE2, TMPRSS2 and dipeptidyl peptidase-4 (DPP4) have been reported to play an important role in the severity of the disease. ${ }^{94}$ It has been established that SARS-CoV-2 uses the receptor ACE2 for entry and TMPRSS2 for S protein priming. ${ }^{91}$ The ACE2 or TMPRSS2 DNA polymorphisms are likely associated with genetic susceptibility to COVID-19. ${ }^{95}$

The gene ApoE, located on $19 q 13.32$, is one of the highly co-expressed genes in type II alveolar cells in the lungs, which has been investigated in regard to COVID-19 prognosis. ${ }^{96}$ Kuo et al. showed that the ApoE e4 genotype predicted severe COVID-19 in the UK Biobank community cohort independently of the pre-existing CVD, dementia and type 2 diabetes. ${ }^{97}$ Variations in human leukocyte antigen (HLA) have also been determined concerning the identification of individuals at higher risk of the disease. ${ }^{98}$ HLA-B*46:01 had the fewest predicted binding peptides for SARS-CoV-2, suggesting that individuals with this allele could be particularly vulnerable to COVID-19. Conversely, HLA-B*15:03 showed the greatest capacity to present highly conserved SARS-CoV-2 peptides, which are shared among common human coronaviruses. ${ }^{98}$ The 3p21.31 gene cluster has been identified as a genetic susceptibility locus in patients with COVID-19-dependent respiratory failure. The potential involvement of the $\mathrm{ABO}$ blood group system was confirmed in a study involving 1,980 patients with COVID-19 and a severe disease course, defined as respiratory failure. ${ }^{87}$

Recently, there has been much interest in interferon (IFN) research in regard to the SARS-CoV-2 infection. Available data implicates the importance of type I IFN (IFN-I) signaling, including defects in IFN-I gene expression in defense against the SARS-CoV-2 infection, and suggests that the inherited deleterious variants may explain the subset of severe COVID-19. ${ }^{99}$ Zhang et al. and Bastard et al. revealed mutations in genes that belong to the Toll-like receptor 3 (TLR3) and IFN-I signaling pathways, leading to undetectable levels of interferon alpha (IFN- $\alpha$ ) in blood plasma during coronavirus infection, thus linking the mutations to defective IFN- $\alpha$ production and COVID-19 severity. ${ }^{99,100}$ It has been shown that the degree of an increase of uracil in SARS-CoV-2 variants correlates with the enhanced production of TNF- $\alpha$ and IL-6 when compared with stimulation with the singlestranded RNA (ssRNA) sequence of the virus isolated in Wuhan. Thus, RNA editing has been stated a factor for mutation bias in SARS-CoV-2 variants, which could affect the production of host inflammatory cytokines and influence SARS-CoV-2 overreactivity. ${ }^{101}$

The COVID-19 risk factors discussed in this paper are presented comprehensively in Table 1. 


\section{Conclusions}

Coronaviruses, including SARS-CoV-2, are characterized by fewer gene mutations than other RNA viruses. Although differences in within-host diversity between mild and severe COVID-19 cases have been revealed, direct factors determining COVID-19 severity are not yet fully described. Therefore, the accurate evaluation of the role of SARS-CoV-2 variant-dependent and hostdependent risk factors for COVID-19 severity and fatality may help to identify potential drug target candidates for further study and bring hope for a breakthrough in COVID-19 treatment.

Table 1. Risk factors associated with coronavirus disease 2019 (COVID-19)

\begin{tabular}{|c|c|}
\hline Risk factor types & Risk factors \\
\hline $\begin{array}{l}\text { Demographic } \\
\text { and social }\end{array}$ & $\begin{array}{l}\text { - older age } \\
\text { - male gender } \\
\text { - race (Black, South Asian, minority ethnic groups) } \\
\text { - nursing home residents } \\
\text { - in-center communities (dialysis) }\end{array}$ \\
\hline Clinical & $\begin{array}{l}\text { - obesity } \\
\text { - comorbidities (CVD, HTA, DM, COPD, asthma, } \\
\text { CKD/dialysis, neoplasms, sickle-cell disease } \\
\text { - immunocompromised state from solid-organ } \\
\text { transplant } \\
\text { - dementia } \\
\text { - smoking } \\
\text { - pregnancy } \\
\text { - initial SOFA score }>2 \\
\text { - dyspnea, respiratory rate }>24 \text { breaths/min } \\
\text { - high amount of viral load }\end{array}$ \\
\hline Laboratory & $\begin{array}{l}\text { - elevated classical markers (CRP, ferritin, IL-6, D-dimer, } \\
\text { IL-2, IL-7, IL-10, G-CSF, TNF-a, creatinine, AST, ALT, } \\
\text { blood urea nitrogen, troponin, creatine kinase, HbA } 1 \text { ) } \\
\text { - elevated new markers (IP-10, MCP-1, MIP1A) } \\
\text { - leukocytosis } \\
\text { - lymphopenia } \\
\text { - high neutrophil-to-lymphocyte ratio }\end{array}$ \\
\hline $\begin{array}{l}\text { Human } \\
\text { genetic }\end{array}$ & $\begin{array}{l}\text { - ABO blood group } \\
\text { - Rh positive blood type } \\
\text { - ACE, TMPRSS2, DPP4, ApoE e4 gene polymorphisms } \\
\text { - HLA variations } \\
\text { - defects in IFN-I gene expression }\end{array}$ \\
\hline $\begin{array}{l}\text { SARS-CoV-2 } \\
\text { genetic }\end{array}$ & $\begin{array}{l}\text { - within-host SARS-CoV-2 diversity } \\
\text { - RNA editing } \\
\text { - ACE2 variants (including rs146598386, rs73195521, } \\
\text { rs755766792, etc.) } \\
\text { - ORF3a protein mutations }\end{array}$ \\
\hline
\end{tabular}

SARS-CoV-2 - severe acute respiratory syndrome coronavirus-2 CVD - cardiovascular diseases; HTA - arterial hypertension; DM - diabetes mellitus; COPD - chronic obstructive pulmonary disease; CKD - chronic kidney disease; SOFA - Sequential Organ Failure Assessment; CRP - C-reactive protein; IL - interleukin; G-CSF - granulocyte colony-stimulating factor; TNF-a - tumor necrosis factor alpha; AST - aspartate aminotransferase; ALT - alanine aminotransferase; $\mathrm{HbA}_{1 c}$ - glycated hemoglobin; IP-10 - interferon gamma-inducible protein-10; MCP-1 - monocyte chemoattractant protein-1; MIP1A - macrophage inflammatory protein 1alpha; ACE - angiotensin-converting enzyme;TMPRSS2 - transmembrane protease serine 2; DPP4 - dipeptidyl peptidase-4; HLA - human leukocyte antigen; IFN-I - type I interferon; ACE2 - angiotensin-converting enzyme 2.

\section{ORCID iDs}

Helena Martynowicz (D) https://orcid.org/0000-0003-1283-8460 Anna Jodkowska (D) https://orcid.org/0000-0001-8650-1196 Rafał Poręba (iD https://orcid.org/0000-0002-7217-7070 Grzegorz Mazur (1) https://orcid.org/0000-0001-6610-2008 Mieszko Więckiewicz (1) https://orcid.org/0000-0003-4953-7143

\section{References}

1. WHO Coronavirus Disease (COVID-19) Dashboard. https://covid19.who.int/. Updated November 19, 2020, 5:13 p.m. CET.

2. Giovanetti M, Benvenuto D, Angeletti S, Ciccozzi M. The first two cases of 2019-nCoV in Italy: Where they come from? J Med Virol. 2020;92(5):518-521. doi:10.1002/jmv.25699

3. Paraskevis D, Kostaki EG, Magiorkinis G, Panayiotakopoulos G, Sourvinos G, Tsiodras S. Full-genome evolutionary analysis of the novel coronavirus (2019-nCoV) rejects the hypothesis of emergence as a result of a recent recombination event. Infect Genet Evol. 2020;79:104212. doi:10.1016/j.meegid.2020.104212

4. Benvenuto D, Giovanetti $M$, Salemi $M$, et al. The global spread of 2019-nCoV: A molecular evolutionary analysis. Pathog Glob Health. 2020;114(2):64-67. doi:10.1080/20477724.2020.1725339

5. Chan JFW, Yuan S, Kok KH, et al. A familial cluster of pneumonia associated with the 2019 novel coronavirus indicating personto-person transmission: A study of a family cluster. Lancet. 2020;395(10223):514-523. doi:10.1016/S0140-6736(20)30154-9

6. Bai Y, Yao L, Wei T, et al. Presumed asymptomatic carrier transmission of COVID-19. JAMA. 2020;323(14):1406-1407. doi:10.1001/jama.2020.2565

7. Yu P, Zhu J, Zhang Z, Han Y. A familial cluster of infection associated with the 2019 novel coronavirus indicating possible personto-person transmission during the incubation period. $J$ Infect Dis. 2020. doi:10.1093/infdis/jiaa077

8. Liu YC, Liao CH, Chang CF, Chou CC, Lin YR. A locally transmitted case of SARS-CoV-2 infection in Taiwan. NEnglJMed. 2020;382(11):1070-1072. doi:10.1056/NEJMc2001573

9. Guan WJ, Ni ZY, Hu Y, et al. Clinical characteristics of coronavirus disease 2019 in China. N Engl J Med. 2020;382(18):1708-1720. doi:10.1056/NEJMoa2002032

10. Huang C, Wang Y, Li X, et al. Clinical features of patients infected with 2019 novel coronavirus in Wuhan, China. Lancet. 2020;395(10223):497-506. doi:10.1016/S0140-6736(20)30183-5

11. Grifoni A, Weiskopf D, Ramirez SI, et al. Targets of T cell responses to SARS-CoV-2 coronavirus in humans with COVID-19 disease and unexposed individuals. Cell. 2020;181(7):1489-1501.e15. doi:10.1016/j.cell.2020.05.015

12. Kreer $C$, Zehner $M$, Weber $T$, et al. Longitudinal isolation of potent near-germline SARS-CoV-2-neutralizing antibodies from COVID-19 patients. Cell. 2020;182(4):843-854.e12. doi:10.1016/j.cell.2020.06.044

13. Sette A, Crotty S. Pre-existing immunity to SARS-CoV-2: The knowns and unknowns. Nat Rev Immunol. 2020;20(8):457-458. doi:10.1038/s41577-020-0389-z

14. Richardson S, Hirsch JS, Narasimhan M, et al. Presenting characteristics, comorbidities, and outcomes among 5700 patients hospitalized with COVID-19 in the New York City area. JAMA. 2020;323(20):2052-2059. doi:10.1001/jama.2020.6775

15. Jesenak $M$, Brndiarova $M$, Urbancikova $I$, et al. Immune parameters and COVID-19 infection - associations with clinical severity and disease prognosis. Front Cell Infect Microbiol. 2020;10:364. doi:10.3389/fcimb.2020.00364

16. Fauci AS, Lane HC, Redfield RR. Covid-19 - navigating the uncharted. New Engl J Med. 2020;382(13):1268-1269. doi:10.1056/NEJMe2002387

17. Grasselli G, Zangrillo A, Zanella A, et al. Baseline characteristics and outcomes of 1591 patients infected with SARS-CoV-2 admitted to ICUs of the Lombardy region, Italy. JAMA. 2020;323(16):1574-1581. doi:10.1001/jama.2020.5394

18. Zhang J, Wang $X$, Jia $X$, et al. Risk factors for disease severity, unimprovement, and mortality in COVID-19 patients in Wuhan, China. Clin Microbiol Infect. 2020;26(6):767-772. doi:10.1016/j.cmi.2020.04.012

19. Hong D, Long L, Wang AY, et al. Kidney manifestations of mild, moderate and severe coronavirus disease 2019: A retrospective cohort study. Clin Kidney J. 2020;13(3):340-346. doi:10.1093/ckj/sfaa083 
20. Oran DP, Topol EJ. Prevalence of asymptomatic SARS-CoV-2 infection. A narrative review. Ann Intern Med. 2020;173(5):362-367. doi:10.7326/M20-3012

21. Chen N, Zhou M, Dong X, et al. Epidemiological and clinical characteristics of 99 cases of 2019-novel coronavirus pneumonia in Wuhan, China: A descriptive study. Lancet. 2020;395(10223):507-513. doi:10.1016/S0140-6736(20)30211-7

22. Jin $\mathrm{YH}, \mathrm{Cai} \mathrm{L}$, Cheng ZS, et al. A rapid advice guideline for the diagnosis and treatment of 2019 novel coronavirus (2019-nCoV) infected pneumonia (standard version). Mil Med Res. 2020;7(1):4. doi:10.1186/s40779-020-0233-6

23. Duan J, Wang X, Chi J, et al. Correlation between the variables collected at admission and progression to severe cases during hospitalization among patients with COVID-19 in Chongqing. J Med Virol. 2020;92(11):2616-2622. doi:10.1002/jmv.26082

24. Chen G, Wu D, Guo W, et al. Clinical and immunological features of severe and moderate coronavirus disease 2019. J Clin Invest. 2020;130(5):2620-2629. doi:10.1172/JCI137244

25. Wu Y, Feng Z, Li P, Yu Q. Relationship between ABO blood group distribution and clinical characteristics in patients with COVID-19. Clin Chim Acta. 2020;509:220-223. doi:10.1016/j.cca.2020.06.026

26. Bhat $R$, Hamid A, Kunin JR, et al. Chest imaging in patients hospitalized with COVID-19 infection - a case series. Curr Probl Diagn Radiol. 2020;49(4):294-301. doi:10.1067/j.cpradiol.2020.04.001

27. Salamanna F, Maglio M, Landini MP, Fini M. Platelet functions and activities as potential hematologic parameters related to Coronavirus Disease 2019 (Covid-19). Platelets. 2020;31(5):627-632. doi:10.1080/09537104.2020.1762852

28. Marini JJ, Gattinoni L. Management of COVID-19 respiratory distress. JAMA. 2020;323(22):2329-2330. doi:10.1001/jama.2020.6825

29. Kalil AC. Treating COVID-19 - off-label drug use, compassionate use, and randomized clinical trials during pandemics. JAMA. 2020;323(19):1897-1898. doi:10.1001/jama.2020.4742

30. FitzGerald GA. Misguided drug advice for COVID-19. Science. 2020;367(6485):1434. doi:10.1126/science.abb8034

31. Liu K, Chen Y, Lin R, Han K. Clinical features of COVID-19 in elderly patients: A comparison with young and middle-aged patients. J Infect. 2020;80(6):e14-e18. doi:10.1016/j.jinf.2020.03.005

32. Simonnet $A$, Chetboun M, Poissy J, et al. High prevalence of obesity in severe acute respiratory syndrome coronavirus-2 (SARS-CoV-2) requiring invasive mechanical ventilation. Obesity (Silver Spring). 2020;28(7):1195-1199. doi:10.1002/oby.22831

33. Anderson MR, Geleris J, Anderson DR, et al. Body mass index and risk for intubation or death in SARS-CoV-2 infection. A retrospective cohort study. Ann Intern Med. 2020. doi:10.7326/M20-3214

34. Epidemiology Working Group for NCIP Epidemic Response, Chinese Center for Disease Control and Prevention. The epidemiological characteristics of an outbreak of 2019 novel coronavirus disease (COVID-19) in China [in Chinese]. Zhonghua Liu Xing Bing Xue Za Zhi. 2020;41(2):145-151. doi:10.3760/cma.j.issn.0254-6450.2020.02.003

35. Corbett RW, Blakey S, Nitsch D, et al.; West London Renal and Transplant Centre. Epidemiology of COVID-19 in an urban dialysis center. J Am Soc Nephrol. 2020;31(8):1815-1823. doi:10.1681/ASN.2020040534

36. Bigelow BF, Tang $\mathrm{O}$, Toci GR, et al. Transmission of SARS-CoV-2 involving residents receiving dialysis in a nursing home - Maryland, April 2020. MMWR Morb Mortal Wkly Rep. 2020;69:1089-1094. doi:10.15585/mmwr.mm6932e4

37. Smith AA, Fridling J, Ibhrahim D, Porter PS Jr. Identifying patients at greatest risk of mortality due to COVID-19: A New England perspective. West J Emerg Med. 2020;21(4):785-789. doi:10.5811/westjem.2020.6.47957

38. Figliozzi S, Masci PG, Ahmadi N, et al. Predictors of adverse prognosis in COVID-19: A systematic review and meta-analysis. Eur J Clin Investig. 2020;50(10):13362. doi:10.1111/eci.13362

39. Butt N, Arshid A, Ahmad SA, Khalid N, Kayani WT. Cardiovascular complications in COVID-19. Am J Emerg Med. 2020. doi:10.1016/j.ajem.2020.07.032

40. Emami A, Javanmardi F, Pirbonyeh N, Akbari A. Prevalence of underlying diseases in hospitalized patients with COVID-19: A systematic review and meta-analysis. Arch Acad Emerg Med. 2020;8(1):e35. PMCID:PMC7096724
41. Zhou Y, Yang Q, Chi J, et al. Comorbidities and the risk of severe or fatal outcomes associated with coronavirus disease 2019: A systematic review and meta-analysis. Int J Infect Dis. 2020;99:47-56. doi:10.1016/j.ijid.2020.07.029

42. Atkins JL, Masoli JAH, Delgado J, et al. Preexisting comorbidities predicting COVID-19 and mortality in the UK biobank community cohort. J Gerontol A Biol Sci Med Sci. 2020;75(11):2224-2230. doi:10.1093/gerona/glaa183

43. Williamson EJ, Walker AJ, Bhaskaran K, et al. Factors associated with COVID-19-related death using OpenSAFELY. Nature. 2020;584(7821):430-436. doi:10.1038/s41586-020-2521-4

44. Kuderer NM, Choueiri TK, Shah DP, et al. Clinical impact of COVID-19 on patients with cancer (CCC19): A cohort study. Lancet. 2020;395(10241):1907-1918. doi:10.1016/S0140-6736(20)31187-9

45. van Dam PA, Huizing M, Mestach G, et al. SARS-CoV-2 and cancer: Are they really partners in crime? Cancer Treat Rev. 2020;89:102068. doi:10.1016/j.ctrv.2020.102068

46. Li X, Xu S, Yu M, et al. Risk factors for severity and mortality in adult COVID-19 inpatients in Wuhan. J Allergy Clin Immunol. 2020;146(1):110-118. doi:10.1016/j.jaci.2020.04.006

47. Yang J, Zheng Y, Gou X, et al. Prevalence of comorbidities and its effects in patients infected with SARS-CoV-2: A systematic review and metaanalysis. Int J Infect Dis. 2020;94:91-95. doi:10.1016/j.ijid.2020.03.017

48. Shao S, Zhao Z, Wang F, et al. Risk factors associated with disease aggravation among 126 hospitalized patients with COVID-19 in different places in China: A retrospective observational study. Medicine (Baltimore). 2020;99(45):e22971. doi:10.1097/MD.0000000000022971

49. Xiang YT, Yang Y, Li W, et al. Timely mental health care for the 2019 novel coronavirus outbreak is urgently needed. Lancet Psychiatry. 2020;7(3):228-229. doi:10.1016/S2215-0366(20)30046-8

50. Dent E, Martin FC, Bergman H, Woo J, Romero-Ortuno R, Walston JD. Management of frailty: Opportunities, challenges, and future directions. Lancet. 2019;394(10206):1376-1386. doi:10.1016/S0140-6736(19)31785-4

51. Skloot GS. The effects of aging on lung structure and function. Clin Geriatr Med. 2017;33(4):447-457. doi:10.1016/j.cger.2017.06.001

52. Yoon HJ, Cho SW, Ahn BW, Yang SY. Alterations in the activity and expression of endothelial NO synthase in aged human endothelial cells. Mech Ageing Dev. 2010;131(2):119-123. doi:10.1016/j.mad.2009.12.010

53. Zhou F, Yu T, Du R, et al. Clinical course and risk factors for mortality of adult inpatients with COVID-19 in Wuhan, China: A retrospective cohort study. Lancet. 2020;395(10229):1054-1062. doi:10.1016/ S0140-6736(20)30566-3

54. Docherty AB, Harrison EM, Green CA, et al. Features of 16,749 hospitalised UK patients with COVID-19 using the ISARIC WHO clinical characterisation protocol. https://www.medrxiv.org/content/10.11 01/2020.04.23.20076042v1. Accessed on May 6, 2020.

55. Radwan NM, Mahmoud NE, Alfaifi AH, Alabdulkareem KI. Comorbidities and severity of coronavirus disease 2019 patients. Saudi Med J. 2020;41(11):1165-1174. doi:10.15537/smj.2020.11.25454

56. Khunti K, Singh AK, Pareek M, Hanif W. Is ethnicity linked to incidence or outcomes of covid-19? BMJ. 2020;369:m1548. doi:10.1136/bmj.m1548

57. Institute for Fiscal Studies (IFS). Are some ethnic groups more vulnerable to COVID-19 than others? https://www.ifs.org.uk/inequality/chapter/are-some-ethnic-groups-more-vulnerable-to-covid19-than-others/. Accessed on December 10, 2020.

58. Lièvre A, Turpin A, Ray-Coquard I; GCO-002 CACOVID-19 collaborators/investigators. Risk factors for Coronavirus Disease 2019 (COVID-19) severity and mortality among solid cancer patients and impact of the disease on anticancer treatment: A French nationwide cohort study (GCO-002 CACOVID-19). Eur J Cancer. 2020;141:62-81. doi:10.1016/j.ejca.2020.09.035

59. Centers for Disease Control and Prevention (CDC): COVID-19. People with certain medical conditions. https://www.cdc.gov/ coronavirus/2019-ncov/need-extra-precautions/people-withmedical-conditions.html. Accessed on April 15, 2020.

60. Bansal R, Gubbi S, Muniyappa R. Metabolic syndrome and COVID 19: Endocrine-immune-vascular interactions shapes clinical course. Endocrinology. 2020;161(10):bqaa112. doi:10.1210/endocr/bqaa112

61. Yang $X, Y u ~ Y, X u ~ J$, et al. Clinical course and outcomes of critically ill patients with SARS-CoV-2 pneumonia in Wuhan, China: A singlecentered, retrospective, observational study. Lancet Respir Med. 2020;8(5):475-481. doi:10.1016/S2213-2600(20)30079-5 
62. Xu XW, Wu XX, Jiang XG, et al. Clinical findings in a group of patients infected with the 2019 novel coronavirus (SARS-Cov-2) outside of Wuhan, China: Retrospective case series. BMJ. 2020;368:m606. doi:10.1136/bmj.m606

63. Chen $T$, Wu D, Chen $\mathrm{H}$, et al. Clinical characteristics of 113 deceased patients with coronavirus disease 2019: Retrospective study. BMJ. 2020;368:m1091. doi:10.1136/bmj.m1091

64. Matsushita K, Ding N, Kou M, et al. The relationship of COVID-19 severity with cardiovascular disease and its traditional risk factors: A systematic review and meta-analysis. Glob Heart. 2020;15(1):64. doi:10.5334/gh.814

65. Meng J, Xiao G, Zhang J, et al. Renin-angiotensin system inhibitors improve the clinical outcomes of COVID-19 patients with hypertension. Emerg Microbes Infect. 2020;9(1):757-760. doi:10.1080/22221751.2020.1746200

66. Wendel Garcia PD, Fumeaux T, Guerci P, et al.; RISC-19-ICU Investigators. Prognostic factors associated with mortality risk and disease progression in 639 critically ill patients with COVID-19 in Europe: Initial report of the international RISC-19-ICU prospective observational cohort. EClinical Medicine. 2020;25:100449. doi:10.1016/j.eclinm.2020.100449

67. Zheng S, Fan J, Yu F, et al. Viral load dynamics and disease severity in patients infected with SARS-CoV-2 in Zhejiang province, China, January-March 2020: Retrospective cohort study. BMJ. 2020;369:m1443. doi:10.1136/bmj.m1443

68. Kavsak PA, De Wit K, Worster A. Emerging key laboratory tests for patients with COVID-19. Clin Biochem. 2020;81:13-14. doi:10.1016/j. clinbiochem.2020.04.009

69. Oudkerk M, Kuijpers D, Oudkerk SF, van Beek E Jr. The vascular nature of COVID-19. Br J Radiol. 2020:93(1113):20200718. doi:10.1259/ bjr.20200718

70. Gupta N, Ish P, Kumar R, et al.; the Safdarjung Hospital Covid Working Group. Evaluation of the clinical profile, laboratory parameters and outcome of two hundred COVID-19 patients from a tertiary centre in India. Monaldi Arch Chest Dis. 2020;90(4). doi:10.4081/monaldi.2020.1507

71. Liu L, Zheng $Y, C$ Cai L, et al. Neutrophil-to-lymphocyte ratio, a critical predictor for assessment of disease severity in patients with COVID-19. Int J Lab Hematol. 2020. doi:10.1111/ijlh.13374

72. Mudatsir M, Fajar JK, Wulandari L, et al. Predictors of COVID-19 severity: A systematic review and meta-analysis. F1000Res. 2020;9:1107. doi:10.12688/f1000research.26186.2

73. Vidali S, Morosetti D, Cossu E, et al. D-dimer as an indicator of prognosis in SARS-CoV-2 infection: A systematic review. ERJ Open Res. 2020;6(2):00260-2020. doi:10.1183/23120541.00260-2020

74. Chen Z, Zhang F, Hu W, et al. Laboratory markers associated with COVID-19 progression in patients with or without comorbidity: A retrospective study. J Clin Lab Anal. 2021;35(1):e23644. doi:10.1002/jcla.23644

75. Barron E, Bakhai C, Kar P, et al. Associations of type 1 and type 2 diabetes with COVID-19-related mortality in England: A wholepopulation study. Lancet Diabetes Endocrinol. 2020;8(10):813-822. doi:10.1016/S2213-8587(20)30272-2

76. Guo W, Li M, Dong Y, et al. Diabetes is a risk factor for the progression and prognosis of COVID-19. Diabetes Metab Res Rev. 2020. doi:10.1002/dmrr.3319

77. Drucker DJ. Coronavirus infections and type 2 diabetes - shared pathways with therapeutic implications. Endocr Rev. 2020;41(3):bnaa011. doi:10.1210/endrev/bnaa011

78. Chen Y, Wang J, Liu C, et al. IP-10 and MCP-1 as biomarkers associated with disease severity of COVID-19. Mol Med. 2020;26:97. doi:10.1186/s10020-020-00230-x

79. Schoeman D, Fielding BC. Coronavirus envelope protein: Current knowledge. Virol J. 2019;16(1):69. doi:10.1186/s12985-019-1182-0

80. Wu A, Peng Y, Huang B, et al. Genome composition and divergence of the novel coronavirus (2019-nCoV) originating in China. Cell Host Microbe. 2020;27(3):325-328. doi:10.1016/j.chom.2020.02.001

81. Wassenaar TM, Zou Y. 2019_nCoV/SARS-CoV-2: Rapid classification of betacoronaviruses and identification of Traditional Chinese Medicine as potential origin of zoonotic coronaviruses. Lett Appl Microbiol. 2020;70(5):342-348. doi:10.1111/lam.13285

82. Tang $X$, Wu C, Li X, et al. On the origin and continuing evolution of SARS-CoV-2. Nat Sci Rev. 2020. doi:10.1093/nsr/nwaa036
83. Al Khatib HA, Benslimane FM, Elbashir IE, et al. Within-host diversity of SARS-CoV-2 in COVID-19 patients with variable disease severities. Front Cell Infect Microbiol. 2020;10:575613. doi:10.3389/fcimb.2020.575613

84. Shikov AE, Barbitoff YA, Glotov AS, et al. Analysis of the spectrum of $A C E 2$ variation suggests a possible influence of rare and common variants on susceptibility to COVID-19 and severity of outcome. Front Genet. 2020;11:551220. doi:10.3389/fgene.2020.551220

85. Liu DX, Fung TS, Chong KKL, Shukla A, Hilgenfeld R. Accessory proteins of SARS-CoV and other coronaviruses. Antiviral Res. 2014;109:97-109. doi:10.1016/j.antiviral.2014.06.013

86. Majumdar P, Niyogi S. ORF3a mutation associated with higher mortality rate in SARS-CoV-2 infection. Epidemiol Infect. 2020;148:e262. doi:10.1017/S0950268820002599

87. Ellinghaus D, Degenhardt F, Bujanda L, et al.; Severe Covid-19 GWAS Group. Genomewide Association study of severe COVID-19 with respiratory failure. N Engl J Med. 2020;383(16):1522-1534. doi:10.1056/NEJMoa2020283

88. Zhao J, Yang $\mathrm{Y}$, Huang $\mathrm{H}$, et al. Relationship between the $A B O$ blood group and the COVID-19 susceptibility. Clin Infect Dis. 2020. doi:10.1093/cid/ciaa1150

89. Zietz M, Zucker J, Tatonetti NP. Testing the association between blood type and COVID-19 infection, intubation, and death. medRxiv. 2020. doi:10.1101/2020.04.08.20058073

90. Vaduganathan M, Vardeny O, Michel T, McMurray JJV, Pfeffer MA, Solomon SD. Renin-angiotensin-aldosterone system inhibitors in patients with Covid-19. N Engl J Med. 2020;382(17):1653-1659. doi:10.1056/NEJMsr2005760

91. Hoffmann M, Kleine-Weber H, Schroeder S, et al. SARS-CoV-2 cell entry depends on ACE2 and TMPRSS2 and is blocked by a clinically proven protease inhibitor. Cell. 2020;181(2):271-280.e8. doi:10.1016/j.cell.2020.02.052

92. Muus C, Luecken MD, Eraslan G, et al. Integrated analyses of singlecell atlases reveal age, gender, and smoking status associations with cell type-specific expression of mediators of SARS-CoV-2 viral entry and highlights inflammatory programs in putative target cells. bioRxiv. 2020. doi:10.1101/2020.04.19.049254

93. Ziegler CGK, Allon SJ, Nyquist SK, et al. SARS-CoV-2 receptor $A C E 2$ is an interferon-stimulated gene in human airway epithelial cells and is detected in specific cell subsets across tissues. Cell. 2020;181(5):1016-1035.e1019. doi:10.1016/j.cell.2020.04.035

94. Choudhary S, Sreenivasulu K, Mitra P, Misra S, Sharma P. Role of genetic variants and gene expression in the susceptibility and severity of COVID-19. Ann Lab Med. 2021;41(2):129-138. doi:10.3343/alm.2021.41.2.129

95. Hou Y, Zhao J, Martin W, et al. New insights into genetic susceptibility of COVID-19: An ACE2 and TMPRSS2 polymorphism analysis. BMC Med. 2020;18(1):216. doi:10.1186/s12916-020-01673-z

96. Zhao Y, Zhao Z, Wang Y, Zhou Y, Ma Y, Zuo W. Single-cell RNA expression profiling of ACE2, the putative receptor of Wuhan 2019-nCov. bioRxiv. 2020. doi:10.1101/2020.01.26.919985

97. Kuo CL, Pilling LC, Atkins JL, et al. APOE e4 genotype predicts severe COVID-19 in the UK Biobank community cohort. J Gerontol A Biol SCi Med Sci. 2020;75(11):2231-2232. doi:10.1093/gerona/glaa131

98. Nguyen A, David JK, Maden SK, et al. Human leukocyte antigen susceptibility map for severe acute respiratory syndrome coronavirus 2 . J Virol. 2020;94(13):e00510-e00520. doi:10.1128/JVI.00510-20

99. Zhang Q, Bastard P, Liu Z, et al. Inborn errors of type I IFN immunity in patients with life-threatening COVID-19. Science. 2020;370(6515):eabd4570. doi:10.1126/science.abd4570

100. Bastard P, Rosen LB, Zhang Q, et al. Autoantibodies against type I IFNs in patients with life-threatening COVID-19. Science. 2020;370(6515):eabd4585. doi:10.1126/science.abd4585

101. Kosuge M, Furusawa-Nishii E, Ito K, Saito Y, Ogasawara K. Point mutation bias in SARS-CoV-2 variants results in increased ability to stimulate inflammatory responses. Sci Rep. 2020;10(1):17766. doi:10.1038/s41598-020-74843-x 